I formed the opinion that he was suffering from brain injury, due either to a fracture or blood clot.

At about 8.30 the character of his respiration began to alter and assume the Cheyne-Stokes character-a condition I had seen in the human subject but never before in animals. Firstly, there was a period of apnoea, enduring for about twelve seconds; during this time the pulse lessened in frequency and became weaker, all movements of the limbs ceased, and he appeared in deep sleep; the number of pulse beats was about 70 .

The second period was indicated by a feeble inspiration, followed by others of an ascending character, and culminating at the sixth with a very deep movement. At each inspiration the pulse gained in frequency and force and the movement of the limbs increased. The number of beats increased to 140 .

The third period was marked by a descending expiratory character, the number of expirations being about six and the final movement almost imperceptible; the pulse decreased in strength, the number of beats falling to seventy, and all movernents ceased gradually.

The time occupied by the second and third period was twelve seconds.

Later on the number of respirations was lessened, still, however occupying the same time. The apnœal periods increased in duration to nearly twenty seconds. Movement of the fore limb ceased, and the hind limb moved but slightly; at I A.M. the fore limb was again moved.

Respiration now became but one deep gasp followed by a deep expiration and one or two shallow movements with a long apnoal period.

At I.30 A.M. he died.

Post-mortem.-All internal organs healthy; some bruising on the frontal bone. There was a large blood clot at the base of the medulla, on the right side just over the origin of the pneumogastric nerve. The whole of the pia mater was much injected.

I shall be glad if anyone can give me any notes on similar cases to the above.

\title{
BILIARY CIRRHOSIS OF THE LIVER IN A HORSEx
}

\section{By Jno. B. Wolstenholme, F.R.C.V.S., Manchester.}

In the British Aredical Journal, i889, vol. i., p. 707, Professor M'Fadyean has described two cases of biliary cirrhosis in horses; and has drawn attention to the fact, that a comparison of pathological conditions in the lower animals, with those in the human subject, has frequently corrected error, and opened a wider field for rescarch.

The veterinary surgeon makes many post-mortem examinations, and is accustomed to frequent surprises thereat, but of all the organs which, in my experience, baffle and confound him who would predict the pathological condition, the liver of the horse stands pre-eminent.

Removed from the effects of alcohol and syphilis; not possessed of a gall-bladder, and therefore rarely the subject of biliary concretions; seldom affected-at least in this country - with fluke worms; rarely invaded with cancer; not subject to mental shocks, and that want of 
exercise so intimately associated with acute yellow atrophy; yet the size, weight, colour, and consistency of the organ vary to an astonishing degree, which in many instances it would have been impossible to have diagnosed during life.

Cirrhosis of the liver in the horse is rarely put on record by the veterinary surgeon, but this is due rather to the want of time to prepare sections and describe their microscopical details, than to infrequency of the affection.

The following particulars are almost identical with those recorded by Professor M'Fadyean, and will be recognised as "biliary" or "hypertrophic" cirrhosis.

On 2oth August last a seven-ycar-old grey cart gelding died after thirty-six hoursillness, with acute abdominal pain, diagnosed as twist of bowels. The autopsy was made four hours afterwards, and revealed a double twist of the double colon. The body was well nourished, there was no ascites, no cedema, no jaundice. The other organs were healthy, with the exception of the liver, which was greatly enlarged, about twice its normal size- -46 lbs. in weight; very dense and firm in texture, so much so that the tissue could not be broken into by pressure with the finger. The capsule smooth, and not thickened; colour, a pale tawny yellow. Some bile in the ducts.

On section the lobules are most distinctly risible to the naked eye, as small brownish areas, surrounded by a greyish material.

On microscopical examination the essential change is readily seen to be that of hypertrophy of the connective-tissue between the lobules, together with the formation of a vast number of bile capillaries, which branch and anastomose in all directions. The lobules are invested singly, rather than in groups-monolobular, in contradistinction to multilobular. Many of the lobules are seen to be invaded by the newly-formed tissue, with the result that portions of lobules are "pinched" off, and may be noticed as areas of liver cells surrounded by connective-tissue and bile capillaries.

Sections prepared with hæmatein render visible many nuclei of the newly-forming connective-tissue, whilst a few of the liver cells are noted to be bile stained. One is struck with the sma!l amount of change the liver cells have undergone, and especially with their clearness, i.e., freedom from granular and fatty matter ; this latter circumstance may possibly be accounted for by fact that no aliment had been ingested for at least thirty-six hours. The entire gland presented the same characteristics throughout.

The horse in question had formed one of some three hundred, where the work is fairly hard, the food of good quality, moderate in quantity, and mixed before reaching the hands of the drivers.

Personally I am in daily contact with the horses and men, and make a weekly inspection of the provender.

It had not been noticed in this case that there had been a capricious appetite, any irregularity of the bowels, loss of energy, or failing in strength. The driver had observed a little yellowness-jaundiceabout the mouth, but had not reported the same.

I am in the habit of making a post-mortem examination of the bodies of most of the horses, and can say that the case is a distinctly isolated one, and that it cannot be considered as enzöotic.

In this Journal for I 888 , p. 305, Dr Greenfield has given a detailed 
account of two cases of cirrhosis of the liver in cats, the microscopical lesions in which are, in many respects, very similar to those I have related. Ascites was, however, a marked feature in the cats, but entirely absent in this horse.

\section{A CASE OF ECZEMA.}

By J. K. BRUCE, M.R.C.V.S., London.

THe subject of this case was a chestnut gelding rising five years old. He was put in a loose-box on the 25 th of October 1894 , on account of having what appeared to be an ordinary cold with a slightly elevated temperature and considerable discharge from the nostrils. When first placed in the loose-box the horse was in very good condition, and his skin was in a perfectly healthy state. In about a fortnight he had recovered from the cold, but a diffuse swelling gradually made its appearance under the thorax. Not much notice was taken of this at first, the horse having a good appetite, normal temperature and regular heart action. The swelling of the chest was followed by filling of the legs and a contemporaneous crop of vesicles all over the body. The vesicles were at first discrete, about the size of lentils, and contained a thin pale yellow fluid which escaped without any pus formation. The vesicles were most pronounced round the nostrils and eyes, inside of arms and thighs, and in the perineum. The fluid, as it escaped from the vesicles, coagulated in the hair, which it matted together. Under the tail and between the thighs masses of soapy-like material collected, made up of shed epidermis and the liquid exudate. The visible mucous membranes appeared normal. The horse fed fairly well, but was dull and had little inclination to move about.

A 4 dram physic ball was administered, and the horse was fed on mashes for a couple of days. After the action of the aloes had passed off, he was washed over, first with soft soap and warm water, and then with creolyn and warm water. Arsenic, in 4 grain doses, was administered thrice daily. The washing of the body was repeated every three days, but without any effect in keeping down the production of the vesicles. The hair was shed very considerably, leaving the skin almost barc; this was most marked under the belly and on the neck. Where the legs were kept bandaged no vesicles were formed and no shedding of epithelium occurred.

The horse continued to feed well, but became emaciated with extraordinary rapidity. The skin was exceedingly tender, the horse flinching whenever he was touched. He gradually acquired a smell just like that of cat's urine. The arsenical powders were continued until the Ioth of December, when he was removed to the Infirmary. Up to this time the skin had never shown any signs of improvement.

On the I ith of December 4 drams of aloes were administered, and this was followed up by 2 ounce doses of sulphate of magnesia twice daily, as recommended by Professor Williams, but the case made no progress, the horse becoming more and mbre emaciated and the slin no better.

After he entered the Infirmary it was observed that he had some difficulty in micturating, and when he did so it was only in small 